\title{
Information Technology in Education - Hopes and Fears
}

\author{
Jan Łaszczyk
}

\begin{abstract}
Modern technologies whose development defines the beginning of the twenty-first century information civilization create entirely new possibilities for organizing and delivering educational processes. Thanks to them an opportunity for education opens up, which is a move away from the narrowly conceived encyclopaedism in education to independent work, revealing activities, and sometimes creativity. The paper will consider the benefits that can be associated with the use of IT in teaching on the one hand understood as a set of devices, on the other as education software packages. At the same time features which entails risks for the organization of teaching and learning processes as well as for themselves educated will be indicated.
\end{abstract}

Keywords - information technology, pedagogy, distance learning, new technologies, Internet, computer, education

\section{INTRODUCTION}

$\mathbf{T}$ HE shape and the results of education determines many factors determining the functioning of the school. Among these factors, a special role is played by the teacher, his personality and qualities but also used methods of education. These methods are modified as a result of technological development, and now in connection with the spread of IT and its means.

Younger representatives of our society are in the majority convinced that IT in our civilization existed almost always. Such beliefs are proved when students are asked the question about the origins of computer science as a discipline. The expression on their faces seems to say: how can we ever ask such a question? It's like asking about the origins of mathematics, philosophy, and natural science, whose creation may interest historians of science but not modern humans, for which the most important are the possibilities of practical use of achievements of these sciences. It can be assumed that such orientation is the result of mastering different dimensions of our lives by means of information technology to the extent that they define the twenty-first century as the era of information and technology used to process that information.

It is, therefore, worth to recall that till the mid-sixties of the last century, the term "computer science" was not present among the Polish language concepts. Professor W. Turski certifies that the word "computer" was first used on a nationwide conference on the mathematical machines carried out in 1968 in Zakopane. At that time, Romuald Marczyński proposed an adoption of the name "computer science" for the discipline, which has been the subject of interest and activity of small group of nameless self-taught. With the formation of

J. Łaszczyk is with the Maria Grzegorzewska Academy of Special Education in Warsaw, laszczyk@aps.edu.pl the new name - as it turned out quite rightly - hope for a more rapid process of self-determination of the discipline and its development was associated at the time.

I refer to genetic thread, but with no taste for the collection and presentation of historical facts. I think we should remember him first and foremost for pragmatic reasons. These make us clearly see that computer science, with less than half a century, is still a very young discipline, and that means that is exposed to the "childhood diseases". It is the age that require a special thought, and even a certain reserve towards the emerging development trends, indulgence but also criticism in relation to the youthful explosions and euphoria, and above all the cool assessment of the value that can be associated with this very dynamic development.

\section{INFORMATION TECHNOLOGY AS A SOURCE OF CHANGE}

In our civilization, progress appears to be autotelic value. Solutions considered to be progressive do not require any additional justifications. Anthropomorphic way of perceiving reality, present not only in the individual dimension but also encoded in a social perspective means that almost every novelty, especially one that results in improved efficiency in individual and group brings practical benefits, increases comfort of living or enhances the scope of our control over the environment, is usually valued positive and does not encourage a deeper analysis of the new far-reaching consequences. The effects of this are numerous and visible. Our delight in the possibilities of the technics and technology did not favor the perception of symptoms indicative of the fact that industrial civilization, evolving for hundreds of years, was on the verge of global collapse. Critical assessment of developments in this civilization emerged processes for good until the end of the twentieth century. In 1998 Stewart Udall, former US congressman, referred to the threats of civilization and uttered the following sentence: "Everything indicates that we have consistently overestimated the contribution of technological progress, and underestimated contribution of natural resources. (...) We need (...) something that we have lost during a run to transform the world: a sense of limits and awareness of the role played by the Earth's resources.[1]

In the area of information and of its resources the progress it is disproportionately faster than the rate of change observed in the industrial society. This rate fascinates us and is not conducive to reflect on its consequences. The belief that we had recently obtained the unimaginable until recently instruments thanks to which you can overcome the current inability tells us to take them almost indiscriminately. What is more, the "technologies" used in the information society appear to be clean. It is widely believed that post-industrial 
society, in which the share of the service activity dominates the manufacturing industries, will consume much less resources. We tend to forget or not even think about that computer, laser printer or copier "(..) contains aluminum probably from Jamaica, Swedish iron, Czech magnesium, Gabonese manganese, Rhodesian chromium, Peruvian zinc, (...) French arsenic, Brazilian tantalum (...) and traces of other metals imported from abroad. Enamel can contail Norwegian titanium, Plastic is made from Middle East oil (...)" [2] The above description shows the geographical extent of the resource base of recently constructed sophisticated devices, but also draws attention to the fact that in fact they come from inside of the Earth, and after their exploiting many of them probably will go back there. Therefore we are not and probably will never be free from threats both in terms of the functioning of the unit as well as globally. To those identified threats, which we can be at least partly overcame, new ones, difficult to identify and to take preventive action are added.

Spread of computers, more precisely personal computers, had caused the phenomenon, which can commonly be called the information revolution. Claiming, that the second information revolution has made up is a starting thesis of many characteristics of modern developed society and even of a civilization. The computer has changed the way of human work, his education, entertainment, leisure and communication. A computer connected to a global network changes all at once, and much more. This "much more" stems from the fact that combining the capabilities of all media, the Internet offers a new quality in the form of the personal involvement of each person in the life of the network and its co-creation.

Education has never been at the forefront of change. On the contrary, its main duty applies to transfer of values and cultural achievements. By its very nature education is so rooted in the past to protect what humanity considers valuable and what can be the foundation for building the future. The thing is, that future must be somehow predictable. Even if not at a level bordering on certainty, it should be at least likely, and even intuitively perceptible. Meanwhile, the world of turning centuries has lost the predictability both in terms of events that we tend to estimate positively (communication of people around the world, communication between people, medicine, comfort of life) as well as in the field of real threats. That unpredictability of the world promotes mans' concentration on the here and now, living in the moment, thinking in the near term perspective. Zygmunt Bauman characterizing the change in the situation of modern man uses the metaphor of the pilgrim and the tourist. Bauman claims that we turned from the pilgrims, knowing where or why do we have to follow, to the tourists, oriented on constant search for new sensations and experiences, choosing from visited sites only those, which are appealing. The tourist is "(...) an exterritorial creature (...) experiencing its extraterritoriality as a privilege and a symptom of independence, as the title to liberty and to freedom of choice; and as an authorization for dalliance with the models of his "own" world. (...) What life equipment (...) of tourist does not contain $(\ldots)$ is the cumbersome, overwhelming, receiving joy of life and looming large in the mind moral responsibility". [7] Responsibility for this, how does the country that tourists come to visit look like. "Ideally: you should be a tourist always and everywhere. Do not belong to the place where you are. Maintain a spiritual distance to and against physical closeness. Behave with reserve. Do not be contagious. Be free - pay in advance for the release of all noncontractual obligations. And the best - apply in advance large amount of sleeping pills to the moral conscience". [8]

Quoted evaluation made by sensitive ethic may seem exaggerated. Let us, therefore, quote a self-reflection of American journalist, which corresponds well with the above theses. "I belong to an entirely new generation of people, a tribe of wanderers. (...) I am a multinational soul on a multinational globe. The entrance to the plane is for me as natural as picking up the telephone handset. I fold myself and carry it with me. I am never surprised. This kind of life gives of course an unprecedented sense of freedom and mobility. We can go through the world as through a fair of miracles, taking something with us at every stop treating the world like a supermarket. We have no home, we have hundreds of houses. (...) But what price do I have to pay for it? (...) Sometimes I wonder if this new kind of existing without affiliation is not strange to something fundamental inside human nature. (...) For what we could die, for which passion we could live, since we never feel the pain of separation and the joy of surprise?" [5]

Can we have an impact on young people in such a culture? Especially when it proclaims the end of its identity, which means that you do not need, and even cannot be the same throughout life, because trying to design your own path is in advance doomed to failure. Instead, we can choose from a variety of possibilities and incarnate in the different roles depending on even the time of day?

After periods of apocalypse between educators doubts have appeared. They concerned whether the adults are still able to bring the world in the tracks of law and order. Criticism of educational guidance that is targeting youth and is conducted by the people responsible for the cruelty, injustice, hypocrisy and falsifying presented models of culture was manifested. [6] Also today there are concepts of negative pedagogy or antipedagogy denying the legitimacy of any planned educational interventions based on the assumption that the child is an imperfect human being in need of adult support specialized in the methods of introducing it in the process of understanding the world. Despite all these stipulations I would like to call loudly with the title of the last book by B. Suchodolski: education in spite of all.

Computers, or more broadly speaking information technology is changing and will continue to change pedagogy, both in its practical as well as conceptual dimension. But the thing is to create conditions for learners to discover and experience not only intellectual, but also aesthetic, artistic, sporting, cultural and social, which will complement the transfer of information.

\section{INFORMATION TECHNOLOGY AND EDUCATION}

You can specify the multiplicity of computer features distinguishing it from other human inventions. Here we would like to point out and emphasize two special features:

1) All the "pre-computer" epoch-making inventions (the steam engine, electricity, transport) supported the power of human muscle. The computer is the first device that on such a large scale enhances the power of human intellect. 
2) All the previous inventions and devices subject to full human control over them. The computer, especially as part of the worldwide network of escapes out of man's control. We observe numerous evidence for that fact.

These two features taken together rise a particular challenge in front of teachers. They call for prudence and far-reaching thinking about computer cognitive activity of a child.

At the same time it is quite widely accepted that one of the characteristic signs of modern education is the use of modern teaching aids in the educational process which, in combination with traditional forms is the basis for the development of multimedia learning strategies. The aim of this course is to provide students access to complementary sources of knowledge and providing them the necessary messages through a variety of media: audio, video and text. So it is a multi-code teaching that contributes to launch a variety of activities of learning children: perceptual, manual, intellectual and emotional. It is widely believed that the implementation of multimedia training, extensive use of new educational technologies and rich media programs contribute greatly to make education interesting and more importantly, leads to the effective implementation of the program content.

Not without significance is the fact that this means for Polish schools getting closer to European standards in the field of broadly understood education. Computers, various multimedia programs - games, popular publications - enable children's full contact with the goods of culture, science and education. They make it easier to pick up a variety of content and contribute to the development of operational thinking, cause and effect thinking and not a fully functioning logical memory, extend the narrowed scope of cognitive interests. They also develop abilities not leading to tiredness and fatigue, because the idea of working with these new media content relies on joy and approval of its actions in a fun atmosphere of play. Without the burden and stress their intellectual effort is sustained with activities consistent with their wishes, and also takes into account the value of teaching, which in turn promotes the discharge of energy, tension, and improves the prestige and self-esteem of peoples with disabilities. Modern educational technologies stimulate cognitive development and satisfy the need of joy. They can also help to reduce shyness and alleviate the fears of the unknown.

Many more potential advantages connected with the computer activity of a person can be mentioned. At the same time a series of warnings and threats arising from the use of the Internet and leading to disruption of physical, social and adverse changes in the psyche of the user it formulated. Effects caused by Internet activity in the intellectual sphere, especially in forming a child's mental structures, are subjected to reflection less frequently. The results of empirical research shows that these effects are entirely real. And let us not be surprised that they arouse hope rather than fear. The ability to model human intelligence is after all his eternal pursuit.

However, it turns out that the brain of a human which uses the Internet operates differently than in case of people that are not using the digital technology. Such thesis is formulated by two researchers from the Los Angeles. It is based on an experiment conducted by themselves, in which two groups of people - one consisting of experienced Internet users and the other consisting novices, using computers for the first time was subjected to special tests. First, participants in both groups were instructed to read a book and during this well-assimilated by all activity brain magnetic resonance imaging (MRI) was performed. It is not hard to guess that among all readers the same neural circuits were active. Differences in brain activity appeared to be significant during searching for information online. Experienced Internet users have used the left frontal cortex party of neural network while among their colleagues this brain region remained completely inactive. In the second part of the experiment, the researchers subjected the novices Internet training: for five consecutive days, five hours a day, the experiment participants worked with a web browser. This time proved to be sufficient to ensure that during the reexamination, MRI among the participants in both groups showed that the same parts of the brain were active. Changes have proven to be fast to obtain and, as examined later, durable. Some experts analyzing the impact of new technologies on the minds of young people believe that there can be different ways of evolution of human brains - another of those who rely on traditional methods of inquiry and other in people using Internet sources, exercising ability of rapid analysis, decision making, associating a variety of information and strong concentration of attention.

We like it or not the flood of information and incentives flowing from the world of media is growing at a terrifying rate. Our attention is almost always tense. The young man is equipped with headphones adjacent to the ear, handy laptop and multifunctional mobile phones already in childhood. Adults even reinforce this style of functioning by promising digital equipment to all pupils in place of textbooks confirming the belief that it is a valuable way of learning. "No one has any doubts that digital technology affects our mental processes. Something as massive as the daily hours of interaction with computers and electronic media must have a perceptible effect. In a sense, this is an experiment on a grand scale, in which we all take part. We educate a new generation in a completely new environment, unable to predict what this will lead". [3]

Recognizing that this statement expresses the extreme position it is impossible not to share the concerns that flow from it.

Asking whether, and how the revolution will affect education, we reach the analogy and ask what influence on the processes of education has had a first information revolution. This, as we know, in Europe is associated with the use of movable font by Gutenberg's printing press.

It is estimated that by the time of Gutenberg on the European continent were ok.30000 books. In 50 years since the submission of the Bible with the help of the new technology of printing, number of books in Europe increased to 9 million. The printing press gave the West more than just the possibility of faster reproduction of books. With the new capabilities knowledge of humanity exceeded the scope of peoples' direct experience. Access to it was gained by the people that were outside of a narrow elite, priesthood elite at that time.

There is no need to prove how this fact influenced the education. Education became widespread causing effects both in terms of what people were taught, as well as ways of organizing the teaching process. Enough to recall that just over 100 years later, J. A. Komeński laid the foundations for the modern pedagogy treating it as the art of teaching "everything to everybody." 
Using this analogy, one must assume that the second information revolution will have an impact on how educational processes will be implemented. What would that impact be? Scenarios can be different. It is important to anticipate them and to prevent those that do not seem to be attractive, at least in today formulated tasks to education.

Information society, more and more often recently called knowledge society, is characterized as one in which knowledge (sometimes reduced to information) is treated as the most important good, which allows a social progress to be implemented. It therefore raises the question of whether knowledge itself is a sufficient factor to achieve the objectives of sustainable social development. This question validates the content of the Lisbon Declaration, and especially how records are translated and developed by interpreters of this document.

A clear hint of rivalry that Europe should take in competition with growing economies and technologies of other continents can be seen in these interpretation. The planned action to bring the EU links closer are to create a European society effectively competing with the US and other rising Asian powers. A knowledge-based economy is to be the measure of this success. This directly raises questions about the desired state and development trends of education.

The recognition that economic and technological development becomes the ultimate goal, or even a goal itself, causes concern that other, traditional values of European civilization, which transfer and fixing served the education, can be forgotten.

In Europe and in European culture, it has always been humanistic reflection and the belief that technology and the economy are no more than tools, so they are menial towards achieving the objectives of substantially different character that dominated the thinking. These fundamental objectives are related to the quality of human life, especially in its spiritual dimension. Such referrals are clearly visible in the educational concepts promoted by Polish teachers, and were reflected in educational practice based on these concepts. The authors of a loud UNESCO report for the International Commission on Education for the twenty-first century edited by J. Delors present a similar "philosophy" of education. In this report, among other things, we find education facing two duties:

- To meet the challenge of effective transfer of more and more knowledge and skills necessary for functioning in the civilization of tomorrow,

- Protect learners against the flood of information coming from different sources, with different values and sometimes questionable level of reliability.

The content of this report indicate that we have faced the task of reconciling the requirements of two civilizations: scientifically - technical and humanistic.

Scientifically-technical civilization implements the principles of pragmatism and focuses on the tangible aspects of human functioning and procedures aimed mainly to provide him appropriate resources. The issue for the operation, materialized values, emotional involvement of a subject and experiencing together, is not only a leading problem, but even a problem worth thinking.

In a humanistic oriented civilization the main regulator of human behavior are the values on the basis of which the community connections are formed. They develop a sense of responsibility for their own fate and the fate of other people. In this civilization, spiritual values are valued higher than instrumental ones, and the guiding principle around which human life is organized is the principle of "to be" and not "to have".

These requirements cause that education has to face specific duties resulting from at least two reasons. Reason one is the dynamics of the development of computer science and information technology, and the rate of change which are inherent to this development, especially the spread of the Internet. The second reason of these particular duties is due to the fact that these resources are interactive. This means that, as never before in the communication process, recipient ceased to be a subject receiving some news passed to him, but became the operating subject that chooses, selects and accepts transfers according to his own wishes, not only like the sender had formed them.

That freedom of choice requires a certain maturity from the subject, especially since it is often the choice of the almost limitless possibilities. The computer serves man information at such big rate that far exceeds our ability of perception. Is difficult to control this avalanche of information even for a bright man capable to quiet, reflective analysis. Young mind, that do not have such ability, cannot manage this onslaught of information. From the simple practical experience we know that we can come back many times to a content of once read and lived novel because we remember them well, sometimes even lifelong. Television transmission in which the boisterous debaters choke each other will be forgotten after a few hours. Metaphor of information fog is an accurate analogy of quantity and quality of information functioning in cyberspace. Bottle of water contains nourishing liquid. The same amount of water smashed into a foggy mist will not save the thirsty wanderer.

Generally, as shown by opinion polls, the teachers perceive more benefits than risks posed by global computer network. First of all, in their opinion, the Internet initiates and supports independent and active work of students, encourages selfeducation and integrates young people. Are the opinions, however, fully justified?

The appearance of the term "electronic encyclopaedism" is a signal of danger of saturation of the students by enormity of information, how often unstructured and unprocessed, and also often simply unnecessary. It is worth to recall the prophetic, as it turns out, the words of Thomas Eliot in this context "Where is the wisdom we have lost in knowledge? Where is the knowledge we have lost in information?" The Internet in its current form is an obvious example of that knowledge begins to die in the vastness of information and wisdom at most gives way to knowledge.

Wisdom and knowledge do not live on the Internet. There, we find only the information, and these are not sufficient to create a reasonable vision of the world.

It is the task and duty of the teacher to conduct student beyond the provided information. It's not easy, because it requires effort and exceeding the ease with which people assimilate information. Questions about what is the world and how to live in this world, and especially how to live with dignity, should not be missing in the educational process, especially when it is conducted with the use of computer resources.

We note that IT education and teaching the use of information technology resources, tends to be locked in a 
world of information. Here are some typical situations in this area: how to install software?, how to paste a drawing?, where to find information on the number of residents of the capital city? etc. Much rarer are naturally occurring teaching situations requiring clarification of mechanisms and understanding dependencies. Even more rarely we reflect on what is the meaning of all the things and whom it has to serve. The danger of treating science and its resources as art for art's sake is not the illusory danger.

"Urging to think you are turning an efficient man to a wise man" says A. Góralski. [8] The lack of such reflection makes a multiplicity of threats posed by information technology more likely. Here are a few:

A huge part of the computer programs are games. Man made them since a long time. Upon the coming of information era leisure was transferred to computer disks. How often the games contain elements of violence and cruelty. They attract lost in the adult world and frustrated young people. They are attractive because they give the feeling of an almost unlimited influence on the fate of the characters and events.

We lack a well-documented findings concerning the negative effects to which an Internet hyperactivity can lead. Phenomenological descriptions show some signs of this activity. Here comes significant and tragic example at the same time.

"A resident of Tokyo posted an advertisement in one of the portals that she seeks comrades to commit suicide. A few days later, she tried to poison herself with pills along with three girls met on the network. Four girls swallowed tablets in a tent, where they kindled a fire in the coal stove. The attempt failed police found the desperate women living. Initiator did not gave up. She posted another announcement, adding that she $<<$ has experience in committing suicide $>>$. Eight volunteers signed up. They rented cars, with which they drove into the mountains, where they decided to kill themselves in a similar manner as before. This time it worked."[9]

It is easy to find many more similar, not less serious cases. They represent a new challenge for all educators, especially those who cannot remain indifferent to them by reason of their profession.

In recent years, in connection with the development of information technology, works on the implementation of educational ideas to the practice of distance education were intensified. This undoubtedly promising form of organizing the teaching - learning process is attracting attention of the organizers and implementers of educational activities. View is established that this new model of education "... becomes fundamental, universal education model of the information society our eyes and with our participation, the development of which must be subject to, and as a consequence - also the result of scientific research."[10] It is worth to make some comments at this point, especially in the context of a postulate to recognize this type of education as a fundamental way of teaching.

One of the fundamental tasks of modern education is to form the world of youth. The importance of this task stems among other things from the fact that the accelerated pace of commonly invoked in almost every area of human life changes can cause, and often evokes a sense of fear of getting lost in the reality in which almost everything is possible, including the total destruction. Man needs some hints as to choose the direction of selectable way of life and objectives that are worth to reach on this way. Growing importance of global moral authorities, letting to engage in spiritual communication and create interpersonal bonds with them is the proof. It is to assume that young people - the subjects of the abovementioned examples (showing behavior of "nonstops" and organizing mass suicide) - are persons who lacked a clear signposts indicating valuable life choices.

School is trying to solve the problem of forming the world of values mainly by persuasion. School is assisted in it by the ideologues of low provenance, taking on the attitude of preaching. Meanwhile, to adopt and shape a value, it is necessary that this value is still alive. Even the most accurately described mountain trail is not able to produce in the listener a passion for mountain tourism. G. Polya says that the examples are better than prescriptions. So let's get to the example showing an effective way of shaping human values. M. K. Stasiak describes an example situation. In 1985 the artist Zbigniew Warpechowski conducted a performance with the participation of colleagues and incidental viewers. The event began when Warpechowski had entered the room naked to the waist and laid on the floor. The woman participating in this action began to beat his naked back with a thick whip. "Nobody in the room reacted. The audience waited for the continuation of the artistic presentation, although the back $\mathrm{Z}$. Warpechowski bloodshot. After about 40 minutes a woman called "Stop beating him!" in a voice full of pain. It was a genuine opposition that became a signal to stop the action."[11]

Let us recall the author's self-reflection, because it is key to understanding this example. "A few days later I realized that Z. Warpechowski put us, the viewers of his performance to the test. He asked us about sensitivity to the suffering, about the proper balance between the values found between artistic action and the dignity of ordinary human suffering. From that experience, I react much faster to human suffering." [12]

Let us ask whether such or similar effect can be achieved in distance education?

\section{ENDING}

The processes of information technology development are irreversible. Computers, or, more broadly speaking, computing resources are changing and will continue to change pedagogy, both in its practical as well as theoretical dimension. The indirect proof is the number of scientific conferences and publications concerning this issue. But the point is that referring to the wording of earlier cited report - it is important to "provide the children and young people all the terms of discovering and experiencing aesthetic, artistic, sporting, scientific, cultural and social experiences, which will complement the transfer of information. More time should be devoted again to art and poetry in school, because in many countries education took on rather utilitarian than cultural character."

These words also apply well to the current situation in Polish schools educating children and young people, but also to the ways of adult education, regardless of branch of education and age of the educated. 


\section{REFERENCES}

[1] D.H. Meadows, D. L. Meadows, J. Randers, „Przekraczanie granic: globalne załamanie czy bezpieczna przyszłość?," Warszawa: Centrum Uniwersalizmu przy Uniwersytecie Warszawskim, 1995, pp. 142

[2] D. H. Meadows, D. L. Meadows, J. Randers, „Przekraczanie...”, pp. 70

[3] Z. Bauman, „Etyka ponowoczesna,” Warszawa: Wydawnictwo Naukowe PWN, 1996, pp. 328, 329

[4] Ibidem, pp. 331

[5] Z. Melosik, „Globalny nastolatek. (Re)konstrukcje tożsamości w ponowoczesnym świecie," Horyzonty Wychowania vol. 2/2002 (3), pp. 138
[6] B. Suchodolski, „Pedagogika,”Warszawa: PWN, 1980

[7] „Newsweek”, 18.01.2009

[8] A. Góralski (Edit.), „Zadanie, metoda, rozwiązanie. Techniki twórczego myślenia," Warszawa: WNT, 1977, pp. 11

[9] „Wprost”, 5 grudnia $2004 \mathrm{r}$,

[10] A. Barczak, J. Florek, S. Jakubowski, T. Sydoruk, „Zdalna edukacja Potrzeby, problemy, szanse i zagrożenia", Warszawa: Wyższa Szkoła Pedagogiki Specjalnej im. Marii Grzegorzewskiej, 2006

[11] M. K. Stasiak, „Twórczy i harmonijny rozwój człowieka,” Łódź: AHE 1993 pp. 103-104

[12] Ibidem, pp. 104 